\title{
Evolução da pesquisa em saúde para reformular as agendas nacionais de saúde*
}

\author{
Carissa Etienne ${ }^{1}$, Kamran Abbasi ${ }^{2}$ e Luis Gabriel Cuervo ${ }^{3}$
}

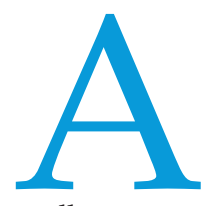

pesquisa em saúde é o eixo central de sistemas de saúde eficazes e eficientes. Uma ampla gama de métodos de pesquisa é necessária para melhorar a saúde pública e a equidade, e para compreender os fundamentos econômicos e mecanismos operacionais dos sistemas de saúde. À medida que o acesso ao conhecimento científico cresceu nas últimas décadas, as expectativas quanto à adoção desse conhecimento para melhorar a saúde também aumentaram. As sociedades agora esperam que as decisões sejam informadas pelas melhores evidências, mas a organização e a gestão das pesquisas continuam inadequadas. Por esse motivo, muita pesquisa é desperdiçada ou tem pouco valor. Os patrocinadores de pesquisas não percebem que seus investimentos afetam o desenvolvimento, e podem não ver efeito algum sobre iniciativas de prevenção ou políticas de saúde..$^{1-5}$

Em 2009, os Estados Membros da Organização Pan-Americana da Saúde (OPAS) aprovaram uma política regional para a pesquisa em saúde nas Américas a primeira políticas regional da OMS para este fim. ${ }^{6}$ Foi desenvolvida para se harmonizar com a Estratégia da OMS sobre Pesquisa em Saúde e complementá-la. ${ }^{7}$ Esta coleção especial do BMJ em colaboração com a OPAS (www.bmj .com/health-research-americas) oferece insights e perspectivas a respeito dos

\footnotetext{
* Tradução oficial para o português realizada pela Organização Pan-Americana da Saúde. Em caso de discrepância, prevalecerá a versão original em inglês.
}

avanços obtidos e desafios surgidos após a implementação da política de pesquisa da OPAS. Examinamos o que está por vir, considerando a adoção da Agenda 2030 das Nações Unidas e dos Objetivos de Desenvolvimento Sustentável; os apelos cada vez mais enérgicos por cobertura universal de saúde e fortalecimento dos sistemas de saúde; e a aprovação, em maio de 2018, do $13^{\circ}$ Programa Global de Trabalho da OMS (2019-2023). ${ }^{8}$

A maioria dos países membros da OPAS desenvolveu políticas nacionais de pesquisa em saúde após a implementação da política regional. Porém, algumas destas já caducaram ou estão sendo atualizadas. Em dezembro de 2017, 16 países relatavam contar com uma política nacional de pesquisa para a saúde, além de 18 países da Comunidade do Caribe (CARICOM) que haviam adotado uma política comum. ${ }^{9}$ Ainda assim, existem diferenças marcantes entre os países no tocante à sua capacidade de realizar, usar e organizar as pesquisas em saúde, ou de monitorar sua capacidade de pesquisa. É frequente que os retornos econômicos e de desenvolvimento sobre o investimento sejam obtidos fora da saúde - em outros setores do governo, na sociedade e na economia. ${ }^{10}$ A eliminação da pólio e o acesso ao tratamento do HIV/AIDS, por exemplo, permitiram a centenas de milhares de pessoas viver vidas mais plenas, ser mais produtivas e contribuir mais amplamente para a sociedade..$^{11,12}$

\footnotetext{
Diretora. Organização Pan-Americana da Saúde/ Organização Mundial da Saúde (OPAS/OMS), Washington, DC, EUA.
}

Em alguns locais, a organização e gestão da pesquisa é inexistente, e os benefícios do Big Data, das redes sociais e de outras ferramentas digitais ainda estão à espera de serem aproveitados. As mudanças da era digital ainda não tiveram reflexos no monitoramento e organização da pesquisa em saúde. Ainda assim, já há estruturas e processos para apoiar a pesquisa de implementação, a pesquisa de sistemas de saúde e a pesquisa em saúde pública, prontos para serem aproveitadas pela comunidade de pesquisa. A sociedade, as agências financiadoras e os patrocinadores e participantes de pesquisa verão os produtos e impactos do investimento da região em pesquisa.

Infelizmente, a pesquisa continua sendo uma função de saúde pública bastante débil nas Américas, e isso deve mudar. ${ }^{13} \mathrm{Na}$ última década, os padrões de redação e publicação de pesquisa científica melhoraram e os registros de ensaios conferiram maior transparência à pesquisa; porém, ainda é necessário integrar esses avanços de maneiras que beneficiem os cidadãos, e fazê-lo de maneira uniforme em todos os países. Identificar as lacunas que persistem ajudará a região a enfrentar e eliminar doenças estabelecidas e emergentes, bem como manter ganhos em saúde, equidade e acesso. É necessário um melhor planejamento dos investimentos para que as descobertas se traduzam em ganhos para a saúde pública e para o sistema de saúde. ${ }^{14}$

\footnotetext{
2 Editor executivo. The BMJ, Londres, Reino Unido. Assessor sênior. Pesquisa em Sistemas de Saúde, OPAS/OMS, Washington, DC, EUA. $\triangle$ cuervolu@ paho.org
} 


\section{Quadro 1: Objetivos da política da OPAS para a pesquisa em saúde}

- Promover a geração de pesquisas pertinentes, éticas e de grande qualidade

- Fortalecer a governança da pesquisa e promover a definição de agendas de pesquisa

- Melhorar a competência dos recursos humanos que participam na pesquisa e prestar-lhes maior apoio

- Promover maior eficiência e intensificar as repercussões da pesquisa e a identificação com seus objetivos mediante parcerias eficazes e estratégicas, colaboração, fortalecimento da confiança e participação do público na pesquisa

- Fomentar práticas e padrões ótimos para a pesquisa

- Promover a difusão e utilização dos resultados da pesquisa

Esta coletânea de artigos faz um balanço do progresso obtido desde a introdução da política da OPAS para a pesquisa em saúde, identifica áreas onde os avanços têm sido lentos e discute os desafios ainda por enfrentar. Também são bem-vindos aportes que contribuam para o debate sobre como integrar a pesquisa aos sistemas de saúde, como organizar a pesquisa e como aumentar seu valor nas Américas. Como devemos conformar as equipes de pesquisa em um mundo interconectado, e como podemos aproveitar quaisquer oportunidades que surjam?

A política de pesquisa da OPAS foi delineada com base em uma abordagem sistêmica, com seis objetivos inter-relacionados (Quadro 1); a pesquisa é necessária para o cumprimento das funções centrais da OPAS e da OMS. ${ }^{2,15}$ Buscamos moldar a agenda de pesquisa nas Américas e globalmente - estimulando a geração, tradução e divulgação de conhecimentos valiosos. Pedimos que as outras regiões compartilhem suas histórias e construam uma narrativa comum em prol de melhores sistemas de saúde e de um mundo mais saudável.

Agradecimentos. Agradecemos a Francisco Becerra, Luis Alejandro Salicrup e ao comitê consultivo da OPAS sobre

\section{REFERÊNCIAS}

1. Chalmers I, Bracken MB, Djulbegovic B, et al. How to increase value and reduce waste when research priorities are set. Lancet 2014;383:156-65. 10.1016/S0140-6736 (13)62229-124411644

2. Cochrane AL. Effectiveness and efficiency: random reflections on health services. Nuffield Provincial Hospitals Trust, 1972.

3. Smith R, Rennie D. Evidence based medicine-an oral history. JAMA 2014;311:365-7. 10.1001/jama.2013.2861822 4449049

4. Organização Mundial da Saúde. The Bamako call to action on research for health: strengthening research for health, development, and equity. OMS, 2008.

5. Organização Mundial da Saúde. Bamako call to action urges new approach to research for health. 2008. http://www .who.int/rpc/news/bamako_call_to action/en/

6. Organização Pan-Americana da Saúde. Política sobre pesquisa para a saúde. Documento CD49/10. 2009. http://www.paho .org/hq/dmdocuments/2009/CD49-10-p .pdf?ua $=1$

7. OMS. $63^{\mathrm{a}}$ Assembleia Mundial da Saúde. WHO's roles and responsibilities on health research. Documento A63/22. 2010. http: / / apps.who.int/gb/ebwha/pdf _files/WHA63/A63_22-en.pdf

8. Organização Mundial da Saúde. $13^{\circ}$ Programa Geral de Trabalho 2019-2023: promover a saúde, manter o mundo seguro, servir aos vulneráveis. 2018. http://www.who.int/about/what-we-do /gpw-thirteen-consultation/en/

9. Cuervo LG, Bermúdez-Tamayo C. Desarrollo de la investigación para la salud en Latinoamérica y el Caribe. Colaboración, publicación y aplicación del conocimiento. Gac Sanit 2018;32:206-8. 10.1016/j.gaceta .2018.03.00129728253

10. Greenhalgh T, Raftery J, Hanney S, Glover M. Research impact: a narrative review. BMC Med 2016;14:78. 10.1186/s12916 -016-0620-827211576

11. Thirumurthy H, Galárraga O, Larson B, Rosen S. HIV treatment produces economic returns through increased work and education, and warrants continued US support. Health Aff (Millwood) 2012;31:1470-7. 10.1377/hlthaff.2012.0217 .22778336

12. Zandam $\mathrm{H}$. Life after polio: towards improving the situation of polio survivors. 2015. https://www.twigh.org/twigh -blog-archives/2015/8/25/life-after-polio pesquisa em saúde pelo apoio ao desenvolvimento desta série. A Jorge Barreto pela revisão da tradução.

Conflito de interesses. Lemos e compreendemos a política do $B M J$ a respeito da declaração de interesses e não temos interesses relevantes a declarar.

Procedência do artigo e revisão por pares. Encomendado; não houve revisão por pares externa.

Série Fortalecimiento da pesquisa em saúde nas Américas. Este artigo faz parte de uma série proposta pela OPAS e encomendada pelo BMJ, o qual foi responsável pela revisão por pares, edição e decisão de publicar o artigo, sem participação da OPAS. As despesas referentes à publicação desta série em Open Access foram financiadas pela OPAS. Para ler os outros artigos da série em inglês, visite www.bmj.com/health-research -americas; acesso à série em espanhol e português em https://www.paho.org /journal/es/numeros-especiales/fortal ecimiento-investigacion-para-salud -americas -towards-improving-the-situation-of-polio -survivors

13. Organização Pan-Americana da Saúde. Saúde pública nas Américas: renovação conceitual, avaliação de desempenho e bases para ação. 2002. http://iris.paho .org/xmlui/handle/123456789/2748

14. Organização Mundial da Saúde. Changing mindsets-strategy on health policy and systems research. 2012. http://www.who .int/alliance-hpsr/alliancehpsr_changing mindsets_strategyhpsr.pdf

15. Organização Pan-Americana da Saúde. About the Pan American Health Organization (PAHO). http://www.paho.org /hq/index.php?option=com_content\& view $=$ article \&id $=95 \% 3 \mathrm{~A} 2008$-values -vision-mission\&catid=6822\%3Acorporate -pages\&lang=en.

Como citar (artigo original): BMJ 2018;362:k2944 doi: http:/ /dx.doi.org/10.1136/bmj.k2944

Manuscrito original em inglês publicado em 16 de julho de 2018. 